https://helda.helsinki.fi

Changes in drinking as predictors of changes in sickness absence : a case-crossover study

\title{
Ervasti, Jenni
}

2018-01

Ervasti , J , Kivimaki , M , Pentti , J , Halonen , J I , Vahtera , J \& Virtanen , M 2018 ,

Changes in drinking as predictors of changes in sickness absence : a case-crossover study '

, Journal of Epidemiology \& Community Health , vol. 72 , no. 1 , pp. 61-67 . https://doi.org/10.1136/jech-2017-20977

http://hdl.handle.net/10138/311547

https://doi.org/10.1136/jech-2017-209777

unspecified

acceptedVersion

Downloaded from Helda, University of Helsinki institutional repository.

This is an electronic reprint of the original article.

This reprint may differ from the original in pagination and typographic detail.

Please cite the original version. 
Changes in drinking as predictors of changes in sickness absence: A casecrossover study

Jenni Ervasti, $\mathrm{PhD}^{1}$; Mika Kivimäki, $\mathrm{PhD}^{1-3}$; Jaana Pentti, $\mathrm{BSc}^{3}$; Jaana I. Halonen, $\mathrm{PhD}^{1}$; Jussi Vahtera, $\mathrm{MD}, \mathrm{PhD}^{4}$; Marianna Virtanen, $\mathrm{PhD}^{1}$

${ }^{1}$ Finnish Institute of Occupational Health, Helsinki, Finland

${ }^{2}$ Department of Epidemiology and Public Health, University College London, UK

${ }^{3}$ Clinicum, Faculty of Medicine, University of Helsinki, Finland

${ }^{4}$ Department of Public Health, University of Turku and Turku University Hospital, Turku, Finland

Corresponding author: Dr. Jenni Ervasti, Finnish Institute of Occupational Health, PB 40, FI-00251 Helsinki, Finland, Tel. +358 30474 2806, Email: jenni.ervasti@ttl.fi

Word count: 3000 (excl. abstract (250 words), tables, and references)

Number of references: 42 


\section{ABSTRACT}

Background: We investigated whether changes in alcohol use predict changes in the risk of sickness absence in a case-crossover design.

Methods: Finnish public sector employees were surveyed in 2000, 2004, and 2008 on alcohol use and covariates. Heavy drinking was defined as either a weekly intake that exceeded recommendations (12 units for women; 23 for men) or having an extreme drinking session. The responses were linked to national sickness absence registers (outcome). We analyzed the within-person relative risk of change in the risk of sickness absence in relation to change in drinking. Case periods were those with sickness absence within one year of the survey, and control periods were those without sickness absence within one year of the survey.

Results: Heavy drinking was associated with an increased risk of self-certified short-term (13 days) absence (odds ratio [OR] 1.23, 95\% CI 1.08-1.39 after multivariable adjustments); with a higher risk observed among those who increased drinking $(\mathrm{OR}=1.27,95 \% \mathrm{CI} 1.07$ 1.52) and a lower risk among those who decreased drinking ( $\mathrm{OR}=0.81,95 \%$ CI $0.68-0.98)$. The association of increased drinking and short-term absence was more pronounced among men $(\mathrm{OR}=1.61,95 \% \mathrm{CI} 1.18-2.19)$ than among women $(\mathrm{OR}=1.17,95 \%$ CI 1.01-1.35). Both increases $(\mathrm{OR}=1.32,95 \% \mathrm{CI} 1.15-1.51)$ and decreases $(\mathrm{OR}=1.24,95 \% \mathrm{CI} 1.09-1.41)$ in drinking were associated with an increased risk of all-cause medically certified long-term ( $>9$ days) sickness absence.

Conclusion: Increases in drinking were reflected in increases in short- and long-term sickness absences. Men and employees with a low socioeconomic position may particularly be at-risk. 
Key words: Alcohol intake; case-crossover design; Finland; injury; mental health; poisoning; occupational position; sex differences; sickness absence; socioeconomic gradient

What is already known on this subject?

Studies support the association between alcohol use and sickness absence. However, previous studies have had limitations regarding measurement of sickness absence and evidence on causality. Moreover, knowledge about vulnerable subgroups particularly at-risk for sickness absence due to heavy drinking is lacking.

What this study adds?

In a case-crossover design, we demonstrate that increased drinking is associated with increased risk of both short- and long-term sickness absence. Individuals with low socioeconomic status were particularly at risk for increased short-term sickness absence and long-term absence due to external causes as a result of changes in drinking pattern. Information about vulnerable groups can be used when developing interventions to prevent alcohol-related absence from work. 


\section{INTRODUCTION}

The costs of alcohol-related sickness absences are estimated to be high.[1,2] A recent review of 28 studies supported the association between alcohol use and absence from work due to sickness.[3] The review also raised the question of the existence of vulnerable groups. Some previous studies have found that heavy drinking men have more sickness absences than heavy drinking women.[4-6] However, other studies have failed to support this, $[7,8]$ or reported no sex differences.[9, 10] People with a low socioeconomic status who drink heavily might also be at an increased risk of sickness absence, but only few studies are available to test this hypothesis.[8, 11]

A largely neglected but plausible moderating factor for the association between alcohol use and sickness absence is the length of the sickness absence period. Short-term sickness absence is often self-certified, and may thus reflect the immediate effects of heavy drinking (e.g., hangover). In contrast, long-term, medically certified absences are a more valid measure of health, and may reflect the long-term alcohol-related disease burden.[12-14] At least one previous study has examined this issue and found a stronger association between alcohol use and short-term absences than between alcohol use and long-term absence episodes.[14]

Previous studies have several limitations. First, sickness absence is often based on selfreports, although objective register data would be more reliable indicators and would prevent misreporting.[6-8] Second, of the 28 studies included in the recent review, only four were longitudinal.[3] Thus, the majority of the studies have been unable to establish temporality 
between alcohol use and sickness absence. Third, few studies have focused on cause-specific sickness absence,[15] although previous research has shown that comorbidity of mental and substance use disorders are common,[16] and that women with a comorbid mental disorder and alcohol dependence have considerably more sickness absences than those with mental health-related problems only.[11] Meta-analyses have also found strong evidence that higher alcohol intake is linked to an increased risk of injury.[17, 18]

To address some of these limitations, we examined how changes in drinking are related to changes in sickness absence over time, using a case-crossover study design in which each case serves as their own control,[19] as shown in Figure 1. This method controls for all measured and unmeasured time-invariant confounders, such as sex, education level, genetic background, and personality by design.[20] In addition to sickness absence due to any cause, we focused on sickness absences due to mental disorder, and injury or poisoning. 


\section{METHODS}

Design

This case-crossover study is nested in the prospective Finnish Public Sector cohort study of employees from 10 municipalities and 21 hospitals,[21] which was approved by the ethics committee of the Hospital District of Helsinki. The eligible population comprised employees who responded to at least two of three questionnaire surveys in 2000, 2004, and 2008, were alive, and not on disability pension one year after their last survey response. We used data from longitudinal cohort study in a case-crossover design, where each individual serves as their "case" (sickness absence within one year of the survey) and "control" (no sickness absence within one year of the survey). We compared the data from the "case" time point to the data from the "control" time point (Figure 1). The design can be used in longitudinal analyses when individuals' outcome statuses change (here change in sickness absence) between the measurement points. This is illustrated in Figure 1 as missing values for IDs \#2, \#4, \#6, \#8, \#9, \#11, \#12. Case-crossover design compares exposure (exposed time vs. unexposed time) before the outcome at case period with exposure at control periods.

Exposure: Heavy drinking

In all surveys, alcohol use was assessed by participants' weekly consumption of alcohol and extreme drinking sessions. One drink was approximately equivalent to one unit or one glass 
of alcoholic drink or $12 \mathrm{~g}$ of alcohol. Alcohol intake was dichotomized into no use or moderate use (a maximum of $140 \mathrm{~g}$, equaling 11.6 units for women; and $280 \mathrm{~g}$, equaling 23.3 units for men) versus greater alcohol use, indicating intake above the recommended limit.[22] The question to elicit an extreme drinking session was: "Have you 'passed out' due to drinking during the past year?" The responses were dichotomized into "never" and "once or more". These two measures were combined into "heavy drinking", defined as either a weekly intake that exceeded recommendations or having an extreme drinking session.[23]

Outcome: Sickness absence

Survey data from 2000, 2004 and 2008 were linked to sickness absence records from employer registers (self-certified short-term absence episodes) and from the Social Insurance Institution (all medically certified episodes of $>9$ days and related diagnoses) through the personal identity number that is unique to each Finnish resident.

We measured absence episodes of one to three days as short-term absence episodes. The number of short-term sickness absence episodes were dichotomized as 0-2 or $>2$ episodes per year. Data on short-term episodes were available for municipal employees only (hospital staff were excluded). Short-term sickness absence data were linked only to the respondents who had given written consent for data linkage (10\% declined) and who remained employed one year after the survey. As regards short-term sickness absence, the eligible population was 22963 employees. 
The Social Insurance Institution register records the beginning and ending dates for all reimbursed episodes of sickness absences that lasted over nine days. The eligible all-cause sickness absence population was 42627 employees. From 2004 onwards, all such episodes have been recorded using ICD-10 -based diagnoses.[24] We used codes F00-F99 to define mental disorder-related sickness absence, and codes S00-T98 to define injury or poisoningrelated sickness absence. The eligible cause-specific sickness absence population was 27189 employees. The number of sickness absence episodes of all-cause, mental disorder and external causes (injury/poisoning) were dichotomized as 0 or $\geq 1$ episode per year.

\section{Covariates}

Covariates were baseline characteristics and potential time-dependent confounding factors measured in 2000, 2004 or 2008. Sex, age (continuous variable) and occupational position based on occupational title (coded as non-manual and manual) were retrieved from the employers' registers. Data on education were obtained from Statistics Finland, and dichotomized into up to 12 years (basic or intermediate education) and over 12 years (high education). In each survey, body mass index $(\mathrm{BMI}=$ weight in kilograms divided by height in meters squared) was dichotomized as less than 30 (non-obese) and 30 or more (obese).[25] Smoking was dichotomized into current smoker and non-smoker (including never smokers and ex-smokers).[26] Participants were categorized as being physically inactive if they reported less than two metabolic equivalent task hours per day (approximately $30 \mathrm{~min}$. of walking) and active if more than this.[27] 
Statistical analyses

We used conditional logistic regression (the LOGISTIC procedure in SAS) to assess the odds of sickness absence at exposed time (i.e., reported heavy drinking) compared to the odds of sickness absence at unexposed time (i.e., reported low-risk drinking). The statistical model was, by design, adjusted for all time-invariant variables in addition to the time of the survey (2000/2004/2008) (Model 1). We additionally adjusted for individual-level time-varying covariates: smoking, BMI, and physical inactivity measured in 2000, 2004 and 2008 (Model 2).

In sensitivity analyses, we tested temporality by analyzing the direction of change in alcohol use. We thus separated participants who had increased ("new heavy drinker", for example ID \#3 and \#7 in Figure 1) from those who reduced their drinking ("former heavy drinker", for example ID \#1 in Figure 1) in the time between two surveys.

We stratified the main analyses by sex, education and occupational position. These subgroups were selected because previous studies have found major differences between the alcohol intake of men and women.[7, 28] While socioeconomic disparities are smaller with regards to alcohol intake,[29, 30] alcohol-related harms have a clear socioeconomic gradient.[31, 32] 
Finally, we examined whether mental (12-item General Health Questionnaire[33]) or somatic health (from medical registers) acted as a mediator in the association between change in drinking and change in sickness absence. These results are presented in online supplements. All the analyses were performed using SAS 9.4 statistical software (SAS Institute Inc., Cary, NC, USA).

\section{RESULTS}

The participants' mean age was $43-44$ years, $77-90 \%$ were women, and $10-23 \%$ were men, depending on the case-crossover sample. The proportion of manual or service workers was $39-48 \%, 47-54 \%$ had less than 12 years of education (basic to intermediate level), and $45-$ $53 \%$ had an education of over 12 years. As regards health behaviors, 22-23\% reported smoking, $12-14 \%$ were obese, and $17-21 \%$ were physically inactive. The prevalence of heavy drinking varied between $15-18 \%$, depending on the sample. Of the participants, $17-$ $20 \%$ changed their drinking status during the time between the two surveys. (Table 1.) The characteristics of excluded population (no changes in outcome variables) are shown in Supplementary Table 1. 
Table 1. Characteristics of study participants at first "case" measurement in each case-crossover sample.

\begin{tabular}{|c|c|c|c|c|c|}
\hline & & $\begin{array}{l}\text { Short-term SA (n=5664- } \\
5809)\end{array}$ & $\begin{array}{l}\text { All-cause SA (n=12752- } \\
13103)\end{array}$ & $\begin{array}{l}\text { Mental SA (n=1464- } \\
1502)\end{array}$ & $\begin{array}{l}\text { SA due to injury/poisoning } \\
(\mathrm{n}=1172-1205)\end{array}$ \\
\hline \multirow[t]{2}{*}{ Number of measurements: } & Two & $51 \%$ & $50 \%$ & $100 \%$ & $100 \%$ \\
\hline & Three & $49 \%$ & $50 \%$ & $0 \%$ & $0 \%$ \\
\hline \multirow[t]{2}{*}{ Sex: } & Men & $14 \%$ & $15 \%$ & $10 \%$ & $23 \%$ \\
\hline & Women & $86 \%$ & $85 \%$ & $90 \%$ & $77 \%$ \\
\hline \multirow[t]{2}{*}{ Occupational position: } & Manual/service & $43 \%$ & $44 \%$ & $39 \%$ & $48 \%$ \\
\hline & Non-manual & $57 \%$ & $56 \%$ & $61 \%$ & $52 \%$ \\
\hline \multirow[t]{2}{*}{ Education: } & $\leq 12$ years & $54 \%$ & $52 \%$ & $47 \%$ & $54 \%$ \\
\hline & $>12$ years & $46 \%$ & $48 \%$ & $53 \%$ & $45 \%$ \\
\hline \multirow[t]{2}{*}{ Smoking: } & Yes & $23 \%$ & $20 \%$ & $22 \%$ & $22 \%$ \\
\hline & No & $77 \%$ & $80 \%$ & $78 \%$ & $78 \%$ \\
\hline \multirow[t]{2}{*}{ BMI: } & $<30$ & $87 \%$ & $86 \%$ & $86 \%$ & $88 \%$ \\
\hline & $\geq 30$ & $13 \%$ & $14 \%$ & $14 \%$ & $12 \%$ \\
\hline \multirow[t]{2}{*}{ Physically active: } & Yes & $81 \%$ & $79 \%$ & $79 \%$ & $83 \%$ \\
\hline & No & $19 \%$ & $21 \%$ & $21 \%$ & $17 \%$ \\
\hline \multirow[t]{2}{*}{ Heavy drinking: } & Yes & $17 \%$ & $15 \%$ & $18 \%$ & $18 \%$ \\
\hline & No & $83 \%$ & $85 \%$ & $82 \%$ & $82 \%$ \\
\hline
\end{tabular}


Change in drinking:

Yes

$19 \%$

$17 \%$

$20 \%$

$20 \%$

No

$81 \%$

$83 \%$

$80 \%$

$80 \%$

Age, mean (SD)

42.9 (7.9)

$44.3(8.2)$

$43.4(7.5)$

43.5 (7.7)

Note. Number of study participants is different by outcome, as only those whose outcome changed were included. Number of participants is presented as a range due to missing information in some of the variables. 
Table 2 shows crude and lifestyle-adjusted estimates for risk of sickness absence by drinking status. Heavy drinking was associated with short-term absences in the adjusted model $(\mathrm{OR}=1.21,95 \% \mathrm{CI} 1.07-1.38)$. For longer episodes, the associations between heavy drinking and sickness absence were non-significant.

In sensitivity analyses, we explored the direction of causality in more detail. First, we included only the employees who had been low-risk drinkers and had become heavy drinkers, i.e., who had increased their drinking. Among them, the odds of short-term absence were 1.27 times higher (95\% CI 1.07-1.52) and the odds of long-term absence 1.38 times higher $(95 \%$ CI 1.21-1.57) than they had been at baseline, at which point these participants had been lowrisk drinkers. Moreover, increase in drinking was associated with lower odds of mental health-related absence $(\mathrm{OR}=0.57,95 \%$ 0.35-0.93). Among employees who had stopped heavy drinking, the odds of short-term absence were lower ( $\mathrm{OR}=0.83,95 \%$ CI $0.68-1.00)$, but the odds of long-term absence were higher ( $\mathrm{OR}=1.27,95 \%$ CI 1.19-1.43) (Table 2). The results were similar after additional adjustment for mental and somatic health (Supplementary Table S2). 
Table 2. Case-crossover analysis of odds ratios with 95\% CI for having sickness absences while being a heavy drinker. Conditional logistic regression.

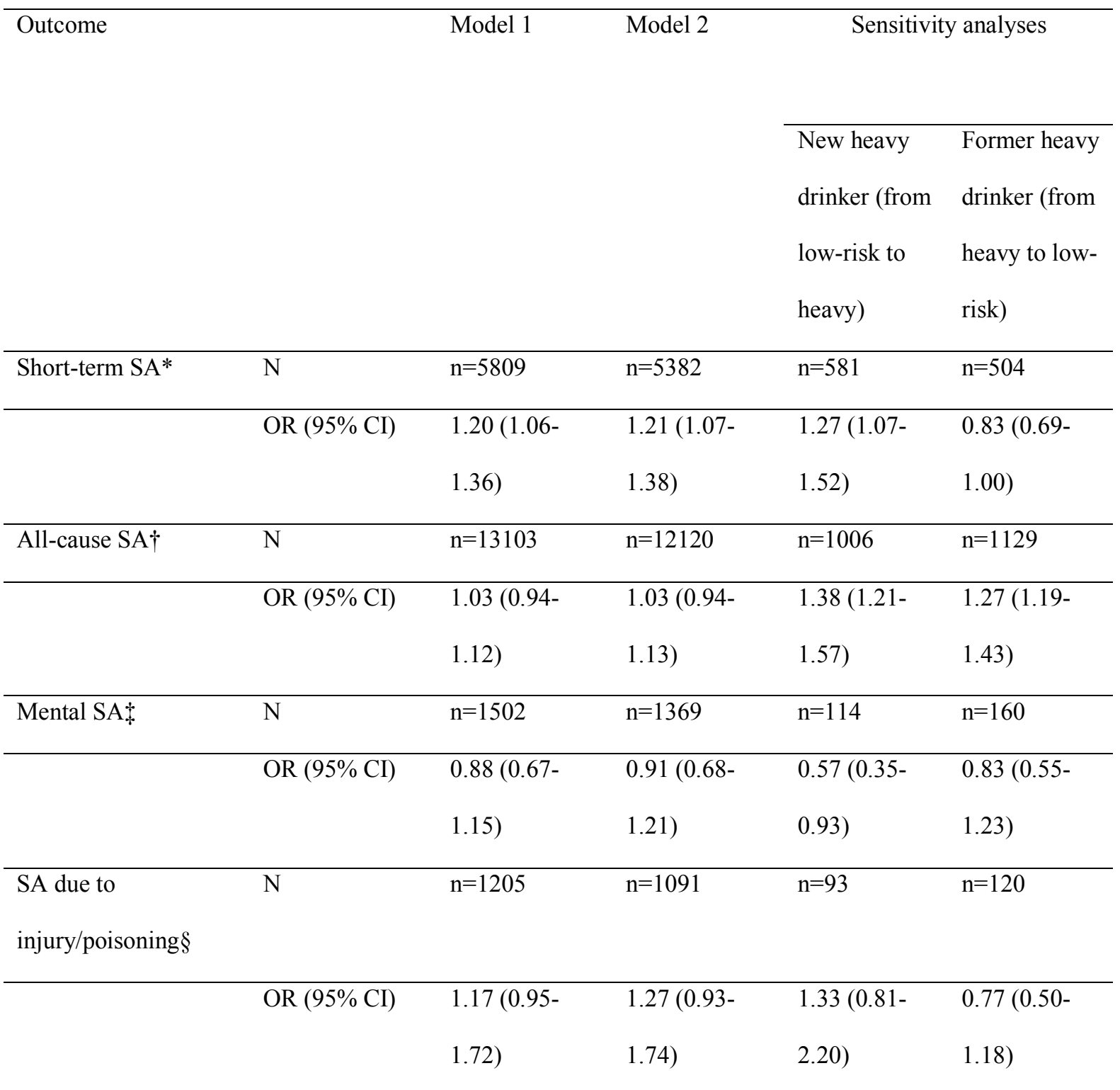

Model 1: Odds ratios for sickness absence outcomes are for heavy drinking compared to low-risk alcohol consumption. Adjusted for measurement phase only.

Model 2: Odds ratios for sickness absence outcomes are for heavy drinking compared to low-risk alcohol consumption. Adjusted for measurement phase, smoking, BMI, and physical inactivity.

Sensitivity analyses: Odds ratio for sickness absence outcomes are for heavy drinking compared to baseline lowrisk ("new heavy drinker") or for low-risk compared to baseline heavy ("former heavy drinker"). Adjusted for measurement phase, smoking, BMI, and physical inactivity.

* 1-3 days sickness absence episodes (0-2 vs. $>2)$

$\dagger>9$ days sickness absence episodes due to any cause (yes vs. no)

$\$>9$ days sickness absence episodes due to mental disorders (yes vs. no)

$\S>9$ days sickness absence episodes due to injury or poisoning (yes vs. no) 
Effect modification by sex was statistically significant regarding the association between heavy drinking and short-term sickness absence $(\mathrm{p}=0.04)$. The adjusted odds of short-term sickness absence were higher among heavy drinking men than among low-risk drinking men $(\mathrm{OR}=1.62 ; 95 \% \mathrm{CI} 1.19-2.21)$. The corresponding odds among women were 1.15 (95\% CI 1.00-1.33). (Table 3.) 
Table 3. Odds ratios with $95 \%$ CI for having sickness absences while being a heavy drinker compared to while being a low-risk drinker. Conditional logistic regression stratified by sex.

\begin{tabular}{|c|c|c|c|c|c|}
\hline Outcome & & Men & & Women & \\
\hline Short-term SA* & $\mathrm{N}$ & $\begin{array}{l}\text { Model } 1 \\
(\mathrm{n}=831)\end{array}$ & $\begin{array}{l}\text { Model } 2 \\
(\mathrm{n}=777)\end{array}$ & $\begin{array}{l}\text { Model } 1 \\
(\mathrm{n}=4978)\end{array}$ & $\begin{array}{l}\text { Model } 2 \\
(\mathrm{n}=4605)\end{array}$ \\
\hline & $\begin{array}{l}\text { OR }(95 \% \\
\text { CI) }\end{array}$ & $\begin{array}{l}1.66(1.23- \\
2.23)\end{array}$ & $\begin{array}{l}1.62(1.19- \\
2.21)\end{array}$ & $1.13(0.99-1.30)$ & $1.15(1.00-1.33)$ \\
\hline All-cause SA $\dagger$ & $\mathrm{N}$ & $\begin{array}{l}\text { Model } 1 \\
(\mathrm{n}=2008)\end{array}$ & $\begin{array}{l}\text { Model } 2 \\
(n=1891)\end{array}$ & $\begin{array}{l}\text { Model } 1 \\
(\mathrm{n}=11095)\end{array}$ & $\begin{array}{l}\text { Model } 2 \\
(\mathrm{n}=10229)\end{array}$ \\
\hline & $\begin{array}{l}\text { OR }(95 \% \\
\text { CI) }\end{array}$ & $\begin{array}{l}1.18(0.98- \\
1.43)\end{array}$ & $\begin{array}{l}1.17(0.96- \\
1.43)\end{array}$ & $1.00(0.90-1.10)$ & $1.00(0.90-1.11)$ \\
\hline Mental SA & $\mathrm{N}$ & $\begin{array}{l}\text { Model } 1 \\
(\mathrm{n}=147)\end{array}$ & $\begin{array}{l}\text { Model } 2 \\
(n=140)\end{array}$ & $\begin{array}{l}\text { Model } 1 \\
(\mathrm{n}=1355)\end{array}$ & $\begin{array}{l}\text { Model } 2 \\
(\mathrm{n}=1229)\end{array}$ \\
\hline & $\begin{array}{l}\text { OR }(95 \% \\
\text { CI) }\end{array}$ & $\begin{array}{l}1.64(0.74- \\
3.59)\end{array}$ & $\begin{array}{l}1.86(0.80- \\
4.33)\end{array}$ & $0.81(0.61-1.09)$ & $0.83(0.61-1.13)$ \\
\hline $\begin{array}{l}\text { SA due to } \\
\text { injury/poisoning§ }\end{array}$ & $\mathrm{N}$ & $\begin{array}{l}\text { Model } 1 \\
(\mathrm{n}=274)\end{array}$ & $\begin{array}{l}\text { Model } 2 \\
(\mathrm{n}=252)\end{array}$ & Model $1(n=931)$ & Model $2(n=839)$ \\
\hline & $\begin{array}{l}\text { OR }(95 \% \\
\text { CI) }\end{array}$ & $\begin{array}{l}1.27(0.70- \\
2.33)\end{array}$ & $\begin{array}{l}1.30(0.69- \\
2.44)\end{array}$ & $1.28(0.91-1.78)$ & $1.27(0.88-1.83)$ \\
\hline
\end{tabular}

Model 1: Crude, adjusted for measurement phase only.

Model 2: Adjusted additionally for smoking, BMI, and physical inactivity.

* 1-3 days sickness absence episodes (0-2 vs. $>2)$

$\dagger>9$ days sickness absence episodes due to any cause (yes vs. no)

$\$>9$ days sickness absence episodes due to mental disorders (yes vs. no)

$\S>9$ days sickness absence episodes due to injury or poisoning (yes vs. no 
Among participants with low to intermediate education, change in drinking was associated with a higher probability of sickness absence due to injury or poisoning $(\mathrm{OR}=1.59,95 \% \mathrm{CI}$ 1.04-2.44), which was not observed among those with a high education (OR $=0.93,95 \% \mathrm{CI}$ 0.58-1.52) (Table 4.). The results were similar when stratified by occupational position. Participants in manual or service jobs who were heavy drinkers had a higher probability of sickness absence due to injury or poisoning $(\mathrm{OR}=1.84,95 \% \mathrm{CI} 1.16-2.92)$ than those in nonmanual occupations (OR=0.90, 95\% CI 0.57-1.42) (Supplementary Table S3). 
Table 4. Odds ratios with 95\% CIs for having sickness absences while being a heavy drinker compared to while being a low-risk drinker. Conditional logistic regression stratified by education.

\begin{tabular}{|c|c|c|c|c|c|}
\hline \multirow[b]{2}{*}{ Short-term SA* } & \multirow[b]{2}{*}{$\mathrm{N}$} & \multicolumn{2}{|c|}{ Low/intermediate $(\leq 12$ years $)$} & \multicolumn{2}{|c|}{ High education ( $>12$ years) } \\
\hline & & $\begin{array}{l}\text { Model } 1 \\
(\mathrm{n}=3104)\end{array}$ & $\begin{array}{l}\text { Model } 2 \\
(\mathrm{n}=2876)\end{array}$ & $\begin{array}{l}\text { Model } 1 \\
(\mathrm{n}=2664)\end{array}$ & $\begin{array}{l}\text { Model } 2 \\
(\mathrm{n}=2483)\end{array}$ \\
\hline & $\begin{array}{l}\text { OR }(95 \% \\
\text { CI) }\end{array}$ & $1.23(1.04-1.46)$ & $1.26(1.02-1.50)$ & $1.17(0.98-1.39)$ & $1.17(0.97-1.41)$ \\
\hline All-cause SA $\dagger$ & $\mathrm{N}$ & $\begin{array}{l}\text { Model } 1 \\
(\mathrm{n}=6722)\end{array}$ & $\begin{array}{l}\text { Model } 2 \\
(\mathrm{n}=6126)\end{array}$ & $\begin{array}{l}\text { Model } 1 \\
(\mathrm{n}=6303)\end{array}$ & $\begin{array}{l}\text { Model } 2 \\
(\mathrm{n}=5918)\end{array}$ \\
\hline & $\begin{array}{l}\text { OR }(95 \% \\
\mathrm{CI})\end{array}$ & $1.02(0.91-1.15)$ & $1.02(0.90-1.16)$ & $1.03(0.91-1.17)$ & $1.04(0.91-1.18)$ \\
\hline Mental SA $\ddagger$ & $\mathrm{N}$ & $\begin{array}{l}\text { Model } 1 \\
(\mathrm{n}=700)\end{array}$ & $\begin{array}{l}\text { Model } 2 \\
(n=626)\end{array}$ & $\begin{array}{l}\text { Model } 1 \\
(\mathrm{n}=795)\end{array}$ & $\begin{array}{l}\text { Model } 2 \\
(n=730)\end{array}$ \\
\hline & $\begin{array}{l}\text { OR }(95 \% \\
\text { CI) }\end{array}$ & $0.78(0.54-1.13)$ & $0.84(0.57-1.25)$ & $0.96(0.64-1.43)$ & $0.95(0.62-1.44)$ \\
\hline $\begin{array}{l}\text { SA due to } \\
\text { injury/poisoning§ }\end{array}$ & $\mathrm{N}$ & $\begin{array}{l}\text { Model } 1 \\
(\mathrm{n}=643)\end{array}$ & $\begin{array}{l}\text { Model } 2 \\
(\mathrm{n}=585)\end{array}$ & $\begin{array}{l}\text { Model } 1 \\
(\mathrm{n}=555)\end{array}$ & $\begin{array}{l}\text { Model } 2 \\
(\mathrm{n}=499)\end{array}$ \\
\hline & $\begin{array}{l}\text { OR }(95 \% \\
\text { CI) }\end{array}$ & $1.59(1.06-2.38)$ & $1.59(1.04-2.44)$ & $0.99(0.64-1.55)$ & $0.93(0.58-1.52)$ \\
\hline
\end{tabular}

Model 1: Crude, adjusted for measurement phase only.

Model 2: Adjusted additionally for smoking, BMI, and physical inactivity.

* 1-3 days sickness absence episodes $(0-2$ vs. $>2)$

$\dagger>9$ days sickness absence episodes due to any cause (yes vs. no)

$\$>9$ days sickness absence episodes due to mental disorders (yes vs. no)

$\S>9$ days sickness absence episodes due to injury or poisoning (yes vs. no 


\section{DISCUSSION}

These within-individual analyses showed that heavy alcohol use, specifically increased heavy drinking, is associated with short-term sickness absence. This pattern was pronounced among men and employees with a low socioeconomic status. The most common reasons for shortterm absences are respiratory (such as a common cold), gastroenteritis (stomach flu), and headache/migraine.[34] Hangover can easily be linked to headache and symptoms of stomach flu. Reduced drinking, in turn, was associated with lower odds of short-term absence.

We found that change in drinking status among men and individuals with a lower socioeconomic status may be more strongly linked with change in short-term sickness absence and sickness absence due to external causes than among women or participants with a higher socioeconomic status. Our results are congruent to an earlier study, which concluded that the strongest association between alcohol use and sickness absence was found among low-educated males.[8] The drinking cultures of socioeconomic groups may differ. While absolute intake of alcohol per week may be similar and above risk levels across socioeconomic strata, employees in lower socioeconomic positions may more often consume all weekly doses at once, which may produce more adverse health consequences than consuming weekly doses on several occasions during one week, at least in the short run. In another study, extended weekends, i.e., short-term absences on Mondays and Fridays, were associated with male sex and lower income, [35] which can indicate differences in the culture of absenteeism. 
Increased drinking was associated with lower odds of mental health-related sickness absences. A previous study found a strong association between alcohol abuse and increased sickness absence among women, which was highlighted in the presence of comorbid mental disorder.[11] Another study found that alcohol use disorder was associated with an increased risk of mental health-related sickness absence, but not with sickness absence due to somatic causes.[36] However, the association between alcohol use disorder and mental health-related sickness absences diluted after adjustment for other mental health-related disorders. The reversed association found in this study was based on a rather small number of observations $(n=114)$ and could be a chance finding, or may be due to the use of psychotropic medication preventing alcohol use. More studies are needed to determine the relationship between alcohol use, mental health and sickness absence.

We found that a change in drinking status was associated with a higher probability of longerterm ( $>9$ days) sickness absences due to external causes, but only among participants with a low socioeconomic status. This indicates a possible socioeconomic gradient in heavy drinking, which is illustrated by a higher rate of injury or poisoning among people with a low socioeconomic status. An alternative explanation is that the likelihood of injuries is lower in office work, which often requires higher education than physically demanding work; similarly it is probably easier to continue working while injured in an office setting.

We found no association between change in alcohol use and change in sickness absences lasting over nine days, although these longer-term medically certified absences have shown to be a global measure of health and to increase the risk of all-cause and cause-specific mortality.[12, 13] However, when controlling for the direction of the change, we found that 
among baseline low-risk drinkers, the odds of sickness absence lasting over nine days increased by one third among those who began to drink above risk levels. Moreover, these odds were also higher among those who had stopped heavy drinking. Thus, quitting drinking is likely to be driven by health impairment, while beginning heavy drinking is likely to lead to health impairment. This is also a potential explanation for the considerably reduced risk of sickness absence due to mental causes among "new" heavy drinkers: A common treatment for mental disorders are antidepressants, an unmeasured time-dependent confounder, with which the use of alcohol should be avoided. The fact that short-term sickness absence, which has a weak association with major chronic diseases, $[12,13]$ increased and decreased in line with drinking habits lends further support to this reasoning. This also corresponds to earlier results,[14] strengthens our conclusions regarding causal associations, and adds novelty to our findings.[3]

Our study has several other strengths. The case-crossover design allowed us to eliminate all time-invariant confounding, such as that due to sex, socioeconomic and genetic background, and personality characteristics, which might have acted as confounders in the association between alcohol use and sickness absence. We were also able to include many time-varying confounders, including smoking, obesity, and physical inactivity. We did not adjust for psychosocial and physical working conditions. However, previous studies have found that adjusting for these have either no effect on or make a weak contribution to the association between alcohol use and sickness absence.[9, 37] Moreover, occupational position can be considered a proxy for physical working conditions. 
The study also has limitations. Alcohol use was obtained from self-reports, which are often underestimated.[21, 37] The associations found may thus be underestimated if the time when a participant is actually a heavy drinker is included in the low-risk drinker time point. However, as we used a within-individual approach, systematic bias is unlikely.

The decision to include abstainers among low-risk drinkers may have deflated our estimates. Abstainers (both never drinkers and former drinkers) have been found to have more sickness absences than moderate drinkers,[21, 37-39] although some studies report no association between abstinence and sickness absence.[14, 40] A recent twin study concluded that the increased risk of sickness absence related to a low use of alcohol is not due to the causal effect of alcohol, but rather to confounding by genetic factors.[41] This result supports our choice to include abstainers in the low-risk group. Important assumptions in case-crossover design are: equal opportunity to be exposed and unexposed during case and control periods, transient exposure, and clearly defined outcome.[42] We controlled for measurement phase in the analyses. As our study population was employed, transient exposure to heavy alcohol use is more probable than chronic substance use disorder (ICD-10: F10). Sickness absence was clearly defined from register data, and results were robust to different cut-points of annual short-term episodes (Supplementary Table S4). Moreover, residual time-dependent confounding is possible. We did not have information e.g., on other substance use. However, we did not find chronic illness or psychiatric distress to affect the observed associations. Finally, the present study was based on a mostly female Finnish public sector employee cohort, which limits the generalizability of the results. 
In conclusion, we found that increased alcohol use was associated with increased risk of both short- and long-term sickness absence. Among participants with a low socioeconomic status, change in drinking was additionally associated with long-term sickness absence due to injury or poisoning. Further research should now determine whether workplace interventions that address the prevention of harmful alcohol use are able to decrease sickness absence rates, and whether people from low socioeconomic status groups benefit more from these interventions than those from high socioeconomic status groups. 
Author contributions: JE, MK, JV, JP, and MV contributed to conception and design. JE analysed the data and drafted the manuscript. All authors contributed either to analysis, interpretation or acquisition of the data, and critically revised the manuscript. All gave final approval and agree to be accountable for all aspects ensuring integrity and accuracy.

Funding: J Ervasti and M Virtanen received funding from the Academy of Finland (\#292824, \#258598). Mika Kivimäki is supported by the NordForsk (the Nordic Programme on Health and Welfare), and J Vahtera received funding from the Academy of Finland (\#264944 and \#267727).

Competing Interest: None declared.

Licence for Publication: The Corresponding Author has the right to grant on behalf of all authors and does grant on behalf of all authors, an exclusive licence (or non exclusive for government employees) on a worldwide basis to the BMJ Publishing Group Ltd to permit this article (if accepted) to be published in JECH and any other BMJPGL products and sublicences such use and exploit all subsidiary rights, as set out in our licence (http://group.bmj.com/products/journals/instructions-for-authors/licence-forms). 


\section{REFERENCES}

1 Baumberg B. The global economic burden of alcohol: a review and some suggestions. Drug and alcohol review 2006;25:537-51.

2

Balakrishnan R, Allender S, Scarborough P, et al. The burden of alcohol-related ill health in the United Kingdom. Journal of public health (Oxford, England) 2009;31:36673.

3 Schou L, Moan IS. Alcohol use-sickness absence association and the moderating role of gender and socioeconomic status: A literature review. Drug and alcohol review 2016;35:158-69.

4 Norstrom T. Per capita alcohol consumption and sickness absence. Addiction (Abingdon, England) 2006;101:1421-7.

5 Norstrom T, Moan IS. Per capita alcohol consumption and sickness absence in Norway. Eur J Public Health 2009;19:383-8.

6 Cunradi CB, Greiner BA, Ragland DR, et al. Alcohol, stress-related factors, and short-term absenteeism among urban transit operators. Journal of urban health : bulletin of the New York Academy of Medicine 2005;82:43-57.

7

Schou LA, Storvoll EE, Moan IS. Alcohol-related sickness absence among young employees: gender differences and the prevention paradox. Eur J Public Health 2014;24:480-5.

8 Johansson E, Bockerman P, Uutela A. Alcohol consumption and sickness absence: evidence from microdata. Eur J Public Health 2009;19:19-22. 

absence: the contribution of working conditions. Scand J Public Health 2009;37:846-54. 10 Hensing G, Holmgren K, Mardby AC. Harmful alcohol habits were no more common in a sample of newly sick-listed Swedish women and men compared with a random population sample. Alcohol and alcoholism (Oxford, Oxfordshire) 2011;46:471-7. or abuse: effects of additional psychiatric disorders. Soc Psychiatry Psychiatr Epidemiol 1998;33:613-9. health: evidence from mortality in the Whitehall II prospective cohort study. BMJ (Clinical research ed) 2003;327:364. among male and female employees. J Epidemiol Community Health 2004;58:321-6. subsequent sickness absence. Scand J Public Health 2015;43:364-72. sickness absence in the GAZEL cohort. Eur J Public Health 2017. mental health problems in the Finnish social and health care system. Scand J Public Health 2016;44:202-8. consumption and the risk of 15 diseases. Preventive medicine 2004;38:613-9. 
Taylor B, Irving HM, Kanteres F, et al. The more you drink, the harder you fall: a systematic review and meta-analysis of how acute alcohol consumption and injury or collision risk increase together. Drug and alcohol dependence 2010;110:108-16.

19 Mittleman MA, Mostofsky E. Exchangeability in the case-crossover design. International journal of epidemiology 2014;43:1645-55.

Allison PD. Fixed effects regression methods in SAS. 2006.

21 Vahtera J, Poikolainen K, Kivimaki M, et al. Alcohol intake and sickness absence: a curvilinear relation. American journal of epidemiology 2002;156:969-76. hoito/Current Care Guidelines: Duodecim 2015. risky alcohol behaviours: a longitudinal study. Addiction (Abingdon, England) 2013;108:3208.

Problems (ICD-10). Geneva, Switzerland: World Health Organization 1994. overweight and obesity in an 8-year follow-up study. Obesity (Silver Spring, Md) 2014;22:1910-7. collaborative meta-analysis of individual-participant data from 140,000 men and women. PLoS One 2012;7:e40101. 

time physical inactivity: an individual-participant meta-analysis of up to 170,000 men and women: the IPD-Work Consortium. American journal of epidemiology 2012;176:1078-89. consequences: Contemporary knowledge and future research considerations. Drug and alcohol dependence 2015;156:1-13. behaviours. Drug and alcohol review 2014;33:588-95. consumption and alcohol-related problems in the study countries of the EU concerted action 'Gender, Culture and Alcohol Problems: a Multi-national Study'. Alcohol and alcoholism (Oxford, Oxfordshire) Supplement 2006;41:i26-36. attributable mortality compared with all-cause mortality: a systematic review and metaanalysis. International journal of epidemiology 2014;43:1314-27. health in 22 European countries. The New England journal of medicine 2008;358:2468-81. GHQ in the WHO study of mental illness in general health care. Psychological medicine 1997;27:191-7. for sickness absence from the Whitehall II Study. Occupational and environmental medicine 1998;55:91-8. 

absenteeism. Occupational and environmental medicine 2001;58:818-22. alcohol use disorders and later cause-specific sick leave in young adult employees. $B M C$ Public Health 2016;15:702. sickness absence from work. Occupational and environmental medicine 2009;66:840-7. 38 Vasse RM, Nijhuis FJ, Kok G. Associations between work stress, alcohol consumption and sickness absence. Addiction (Abingdon, England) 1998;93:231-41. reported alcohol habits, high levels of sickness absence, and disability pensions. J Epidemiol Community Health 1999;53:223-9. absenteeism in the Australian work-place. Addiction (Abingdon, England) 2008;103:738-48. the risk of sickness absence? A discordant twin study. BMC Public Health 2016;16:825. 42 Consiglio GP, Burden AM, Maclure M, et al. Case-crossover study design in pharmacoepidemiology: systematic review and recommendations. Pharmacoepidemiology and drug safety 2013;22:1146-53. 
Figure legends

Figure 1. Fictitious example of participants in case-crossover study on changes in alcohol use as a predictor of changes in sickness absence. 